University of Nebraska - Lincoln

DigitalCommons@University of Nebraska - Lincoln

Publications, Agencies and Staff of the U.S.

Department of Commerce

U.S. Department of Commerce

2013

\title{
Decadal variability of net water flux at the Mediterranean Sea Gibraltar Strait
}

L. Fenoglio-Marc

Technical University Darmstadt, fenoglio@ipg.tu-darmstadt.de

A. Mariotti

NOAA/OAR

G. Sannino

Italian Agency for Energy and Environment (ENEA)

B. Meyssignac

LEGOS/CNES

A. Carillo

Italian Agency for Energy and Environment (ENEA)

See next page for additional authors

Follow this and additional works at: https://digitalcommons.unl.edu/usdeptcommercepub

Part of the Environmental Sciences Commons

Fenoglio-Marc, L.; Mariotti, A.; Sannino, G.; Meyssignac, B.; Carillo, A.; Struglia, M. V.; and Rixen, M., "Decadal variability of net water flux at the Mediterranean Sea Gibraltar Strait" (2013). Publications, Agencies and Staff of the U.S. Department of Commerce. 380.

https://digitalcommons.unl.edu/usdeptcommercepub/380

This Article is brought to you for free and open access by the U.S. Department of Commerce at DigitalCommons@University of Nebraska - Lincoln. It has been accepted for inclusion in Publications, Agencies and Staff of the U.S. Department of Commerce by an authorized administrator of DigitalCommons@University of Nebraska - Lincoln. 


\section{Authors}

L. Fenoglio-Marc, A. Mariotti, G. Sannino, B. Meyssignac, A. Carillo, M. V. Struglia, and M. Rixen 


\title{
Decadal variability of net water flux at the Mediterranean Sea Gibraltar Strait
}

\author{
L. Fenoglio-Marc ${ }^{\text {a,* }}$, A. Mariotti ${ }^{\text {b }}$, G. Sannino ${ }^{\text {c }}$, B. Meyssignac ${ }^{\text {d }}$, A. Carillo ${ }^{\text {c }}$, M.V. Struglia ${ }^{\text {c}}$, M. Rixen ${ }^{\text {e }}$ \\ a Institute of Physical Geodesy, Technical University Darmstadt, Petersenstrasse 13, D-64287 Darmstadt, Germany \\ ${ }^{\mathrm{b}}$ National Oceanic and Atmospheric Administration, Office of Oceanic and Atmospheric Research (NOAA/OAR), 1315 East/West Hwy, Silver Spring, MD 20910, USA \\ c Italian Agency for Energy and Environment (ENEA), Climate Project - Ocean Modelling Unit, Via Anguillarese 301, S.M. di Galeria, I-00060, Roma, Italy \\ d LEGOS/CNES, 14, Avenue E. Belin, 31400 Toulouse, France \\ e World Meteorological Organisation, 7bis, avenue de la Paix, CH-1211 Geneva, Switzerland
}

\section{A R T I C L E I N F O}

\section{Article history:}

Received 15 October 2011

Accepted 23 August 2012

Available online 30 August 2012

\section{Keywords:}

Gibraltar net water flux

Ocean mass change

Sea-level

Water cycle

\begin{abstract}
A B S T R A C T
Long-term variability of the net water flux into the Mediterranean Sea at the Gibraltar Strait over the period 1960-2009 is explored based on an approach combining multiple observational datasets and results from a regional climate model simulation. The approach includes deriving Gibraltar net inflow from the application of the Mediterranean Sea water budget equation using observationally based estimates of mass variation, evaporation, precipitation and simulated river discharge and Bosphorus Strait water fluxes. This derivation is compared with results from a simulation using the PROTHEUS regional ocean-atmosphere coupled model considering both individual water cycle terms and overall Gibraltar water flux.

Results from both methodologies point to an increase in net water flux at Gibraltar over the period 1970-2009 (0.8+/-0.2 mm/mo per year based on the observational approach). Simulated Gibraltar net water flux shows decadal variability during 1960-2009 including a net Gibraltar water flux decrease during 1960-1970 before the 1970-2009 increase.

Decadal variations in net evaporation at the sea-surface, such as the increase during 1970-2009, appear to drive the changes in net inflow at Gibraltar, while river runoff and net inflow at the Bosphorus Strait have a modulating effect. Mediterranean Sea mass changes are seen to be relatively small compared to water mass fluxes at the sea surface and do not show a long-term trend over 1970-2009. The Atlantic Multi-decadal Oscillation (AMO) and the North Atlantic Oscillation (NAO) are relevant indirect influences on net water flux at Gibraltar via the influence they bear on regional evaporation, precipitation and runoff.
\end{abstract}

(c) 2012 Elsevier B.V. All rights reserved.

\section{Introduction}

As the Mediterranean Sea is a semi-enclosed basin, connected with the open Atlantic Ocean only at the Gibraltar Strait, the fluxes of water and salt through this Strait bear a major influence on the state of the Sea with impacts on the mass, salt and energy budgets. A net water inflow at Gibraltar $(G)$ results from incoming fresh and cool Atlantic water and outflowing warm and salty Mediterranean water. Climatologically, net inflow of water at Gibraltar primarily balances the vertical loss of water at the sea-surface (water fluxes through the Bosphorus Strait (B) and river discharge (R) also contribute to balance the surface water loss; e.g. Mariotti et al., 2002). Recent research has shown that decadal changes in net Mediterranean Sea evaporation have characterized the 1958-2006 period, with an overall increase in net evaporation resulting in a substantial increase in sea-surface water loss (Criado-Aldeanueva et al., 2010; Mariotti, 2010). An open question is whether this increased water loss has induced increases in the net water inflow at Gibraltar or whether there have been changes in Mediterranean Sea water mass. In

\footnotetext{
* Corresponding author.

E-mail address: fenoglio@ipg.tu-darmstadt.de (L. Fenoglio-Marc).
}

fact, while the Mediterranean thermohaline circulation is sustained by the atmospheric forcing, its intensity is controlled by the narrow and shallow Strait of Gibraltar via hydraulic control processes (Sannino et al., 2007, 2009a). While measurements of the Mediterranean water outflow through Gibraltar have been collected over short time periods (Sanchez-Roman et al., 2009, Soto-Navarro et al., 2010), there are no long-term direct measurements of net water fluxes. Model simulations have been utilized to improve the understanding of the processes that regulate water fluxes at Gibraltar, with very high-resolution models now able to represent much of the complexity characterizing the dynamics of the Strait and simulate realistic Gibraltar flows (Sannino et al., 2009a; Sanchez-Garrido et al., 2011). It is interesting to note that a common assumption in state-of-art Mediterranean Sea models used for these studies is the "equilibrium condition" which forces the net flow at Gibraltar to strictly compensate the freshwater lost at the sea-surface (e.g. Tonani et al., 2008). Here we stress that such an assumption has still not been verified by specific observations.

Nowadays, changes in Mediterranean Sea mass are directly measured by the satellite gravimetric mission GRACE. These measurements, available over the interval 2002-2010, are usually expressed in terms of changes in equivalent water thickness, i.e. water mass 
changes per surface area (with $1 \mathrm{~mm}$ water column corresponding to $1 \mathrm{~kg} / \mathrm{m}^{2}$ if a density of $1 \mathrm{~g} / \mathrm{cm}^{3}$ is assumed). Mediterranean Sea water mass change values may also be derived from sea level change, provided the steric component of the sea level change can be estimated. In this case the water mass change is directly expressed as water thickness (volume). Recent studies have compared indirect estimates of Mediterranean Sea water mass derived from sea-level by way of steric-corrected satellite altimetry with those based on GRACE satellite mass retrievals. Results indicate a good agreement and a Mediterranean Sea mass increase during the last decade (Calafat et al., 2010; Fenoglio-Marc et al., 2012b).

Mediterranean sea level variability has been shown to be affected by the variability of the North Atlantic Oscillation (NAO; Hurrell et al., 2003) mainly through the impact of atmospheric sea-level pressure changes (Tsimplis and Josey, 2001). Although these results collectively suggest long-term variations in Mediterranean Sea mass and sea-level, and large-scale atmospheric influences, to our knowledge how long-term changes in fresh water fluxes may have affected Gibraltar water fluxes is yet to be explored. The level of accuracy of the satellite-based measurements calls for a re-examination of many conventional approximations often taken for granted (Greatbatch and Lu, 2001).

The goal of this work is to study the decadal variations in net water flux at the Strait of Gibraltar over the period 1960-2009 based on a combined observational-modelling approach and to indirectly explore the correctness of the "equilibrium condition" assumption made in state-of-art models. First, Gibraltar water flux is derived indirectly from the water budget equation based on observational estimates of Mediterranean Sea mass changes (from steric-corrected sea-level estimates and GRACE mass retrievals), regional precipitation and evaporation. Next, an independent estimate of the Gibraltar water flux is obtained from a numerical simulation by a regional ocean-atmosphere climate model. Lastly, potentially important factors regulating long-term Gibraltar flux changes are discussed. The paper is organized as follows: overall data and methodology are described in Section 2; results pertaining Mediterranean Sea mass and Gibraltar water flux variability are presented in Section 3; conclusions are in Section 4.

\section{Methodology and data}

The net water inflow through Gibraltar $(G)$, may be estimated on the basis of the water budget equation for the Mediterranean Sea:

$\mathrm{G}=\mathrm{E}-(\mathrm{P}+\mathrm{R}+\mathrm{B})+\partial \mathrm{M} / \partial \mathrm{t}$

with $\mathrm{E}$ being sea-surface evaporation, $\mathrm{P}$ precipitation over the sea; $\mathrm{R}$ river discharge into the sea from the Mediterranean catchment; $B$ net water influx from the Black Sea at the Bosphorus Strait; $\partial \mathrm{M} / \partial \mathrm{t}$ the rate of Mediterranean Sea water mass (M) change (see also Fenoglio-Marc et al., 2012b; Grayek et al., 2010). (Note that changes in Mediterranean Sea mass due to salinity changes are not accounted for in this water budget equation). As all quantities in Eq. (1) represent a volume variation, they can be expressed as basin-uniform sea level change in units of $\mathrm{mm} / \mathrm{mo}$, We apply Eq. (1) to derive $\mathrm{G}$ based on observational estimates of $\partial \mathrm{M} / \partial \mathrm{t}, \mathrm{E}$ and $\mathrm{P} . \partial \mathrm{M} / \partial \mathrm{t}$ may be derived as the difference of water mass-induced sea level averaged over the sea $\left(\mathrm{S}_{\text {mass }}\right)$ at two following time-steps (Fenoglio-Marc et al. (2007)), as well as estimated from GRACE gravity solutions. In contrast, the independent results from the model simulation are based on the model's assumption, so it is interesting to see how these results compare with the observational estimate of $G$ and whether they can contribute to a qualitative description of long-term variability in Gibraltar water fluxes.

All the quantities in Eq. (1) are estimated indirectly (as explained in the following) and it is clearly a challenge to define long-term changes and uncertainties of any of these quantities, let alone the resulting $\mathrm{G}$ estimate. Nevertheless, we attempt to estimate errors of annual mass-induced sea level $S_{\text {mass }}$ and derivated quantities, namely $\partial \mathrm{M} / \partial \mathrm{t}$ and $\mathrm{G}$. These error estimates are based on either the root mean square (RMS) difference between the various datasets available for a given quantity, or on error propagation considering the various components contributing to a given estimated quantity (see Table 1 for a summary of data used in this study; Tables $2-5$ for associated error estimates). The first method reflects the spread of the datasets, but unknown systematic errors may remain. We account for the temporal autocorrelation of a time series, by using its effective sample size based on the lag-1 autocorrelation coefficient (Santer et al., 2000). The correlation between time-series and its double-sided significance are evaluated. Linear regression is used to estimate the linear trend and its error. We further assess the trend significance by applying the t-test to the ratio between the estimated trend and its error (Fenoglio-Marc et al., 2011). In the error propagation we consider the components to be uncorrelated (Fenoglio-Marc et al., 2006, 2012b).

\subsection{Mediterranean Sea water mass derivation}

During August 2002-December 2009, Mediterranean water mass-induced sea level $\left(S_{\text {mass }}\right)$ may be estimated directly from satellite-based gravity observations retrieved by the GRACE satellite mission ( $S_{\text {mass }}^{g}$ hereafter; Flechtner, 2007; Fenoglio-Marc et al., 2006). Note that since GRACE measures gravity, a priori mass changes detected by GRACE include both the effect of water and salt changes. Over the longer 1970-2009 period, $S_{\text {mass }}$ may be also estimated indirectly from Eq. (2), by correcting the total sea level $\left(S_{\text {tot }}\right)$ for its steric component $\left(\mathrm{S}_{\text {ster }}\right)$ so as to account only for water mass induced sea-level $\left(\mathrm{S}_{\text {mass }}\right)$ :

$\mathrm{S}_{\text {mass }}=\mathrm{S}_{\text {tot }}-\mathrm{S}_{\text {ster }}$

During 1993-2009, $S_{\text {tot }}$ is evaluated from satellite altimetry data $\left(S_{\text {tot }}^{\text {alti }}\right)$. For this derivation we have used along-track data of the Topex/Poseidon, Jason-1, Jason-2 and Envisat altimetry missions from the RADS database (Naeije et al., 2008) and applied the conventional geophysical corrections accounting for the ocean response to atmospheric wind and pressure forcing (atmospheric loading on the sea surface) via the Dynamic Atmospheric Correction (DAC). Grids of 0.5 degrees have been computed and used to evaluate the sea level basin average. Prior to the altimetry era, starting from $1970 \mathrm{~S}_{\text {tot }}$ is derived based on a reconstruction developed by Meyssignac et al. (2011) (hereafter MBMED11). Comparing the MBMED11 basin averaged reconstruction $\left(S_{\text {tot }}^{\text {reco }}\right)$ with a

Table 1

List of data. For the seven fields used in this study : temperature $(T)$, salinity $(S)$, sea level $\left(S_{\text {tot }}\right)$, mass-induced sea level $\left(S_{\text {mass }}\right)$, evaporation $(E)$, precipitation $(P)$, sea level pressure (SLP) the name of the database together with its time interval, spatial and temporal resolutions are given. For the $\mathrm{T}$ and $\mathrm{S}$ fields the maximum depth and the number of levels are given in addition.

\begin{tabular}{lllllll}
\hline $\begin{array}{l}\text { Database } \\
\text { name }\end{array}$ & Field & $\begin{array}{l}\text { Time } \\
\text { interval }\end{array}$ & Grid & $\begin{array}{l}\text { Depth } \\
(\mathrm{m})\end{array}$ & $\begin{array}{l}\text { Levels } \\
\text { Medar/Medatlas }\end{array}$ & $\begin{array}{l}\text { T, S } \\
\text { sameling }\end{array}$ \\
\hline Ishii v6.7 & T, S & $1945-2002$ & $0.2^{\circ} \times 0.2^{\circ}$ & 4000 & 25 & $1 \mathrm{yr}$ \\
MFSTEP/ICBM & T, S & $2000-2006$ & $1^{\circ} \times 1^{\circ}$ & 700 & 16 & 30 days \\
GRACE & $\mathrm{S}_{\text {mass, }}$ & $2002-2009$ & $300 \mathrm{~km}$ & 3850 & 31 & 30 days \\
altimetry & $\mathrm{S}_{\text {tot }}$ & $1993-2009$ & $0.5^{\circ} \times 0.5^{\circ}$ & & & 30 days \\
MBMED11 & $\mathrm{S}_{\text {tot }}$ & $1970-2009$ & $0.5^{\circ} \times 0.5^{\circ}$ & & & 30 days \\
Protheus & $\mathrm{E}$ & $1958-2001$ & $30 \mathrm{~km}$ & & & 30 days \\
OAFLUX & $\mathrm{E}$ & $1958-2009$ & $1^{\circ} \times 1^{\circ}$ & & & 30 days \\
Protheus & $\mathrm{P}$ & $1958-2001$ & $30 \mathrm{~km}$ & & & 30 days \\
GPCP & $\mathrm{P}$ & $1979-2009$ & $2.5^{\circ} \times 2.5^{\circ}$ & & & 30 days \\
REOFS & $\mathrm{P}$ & $1960-2009$ & $5^{\circ} \times 5^{\circ}$ & & & 30 days \\
HadSLP & $\mathrm{SLP}$ & $1960-2009$ & $5^{\circ} \times 5^{\circ}$ & & & \\
\hline
\end{tabular}


Table 2

Correlation (Corr), root mean square difference (RMSD), number of samples (N) and level of significance of correlation (Significance) of annual time-series in common interval (Time Interval). Units are $\mathrm{mm}$ for sea-level $(\mathrm{S})$ quantities and $\mathrm{mm} / \mathrm{mo}$ for precipitation/evaporation rates and rate of mass change $\partial \mathrm{M} / \partial \mathrm{t}$. For sea level the component type is indicated by the subscript (tot: total sea level; ster: steric sea level; thermo-ster: thermo-steric sea level; halo-ster: halo-steric sea level; mass: mass induced sea level). The superscript indicates the dataset used (e.g. alti: altimetric sea level; reco: reconstructed sea level etc.; see text). For precipitation and evaporation the datasets used are indicated by the subscript.

\begin{tabular}{|c|c|c|c|c|c|c|}
\hline & & Corr & RMSD & $\mathrm{N}$ & $\begin{array}{l}\text { Time } \\
\text { interval }\end{array}$ & $\begin{array}{l}\text { Significance } \\
(\%)\end{array}$ \\
\hline$S_{\text {tot }}^{\text {alti }}$ & $\mathrm{S}_{\text {tot }}^{\text {reco }}$ & 0.98 & 4.0 & 13 & 1993-2002 & 99 \\
\hline $\mathrm{S}_{\text {tot }}^{\text {reco }}$ & $S_{\text {tot }}^{\text {reco_alti }}$ & 0.95 & 9.0 & 13 & 1993-2002 & 99 \\
\hline$S_{\text {ster }}^{\text {ishii }}$ & $\mathrm{S}_{\text {ster }}^{\text {medar }}$ & 0.57 & 12.0 & 57 & 1945-2002 & 99 \\
\hline $\mathrm{S}_{\text {thhii }}^{\text {isho-ster }}$ & $\mathrm{S}_{\text {thermo-ster }}^{\text {medar }}$ & 0.82 & 5.1 & 57 & $1945-2002$ & 99 \\
\hline Sishii & S medar & 0.36 & 12.0 & 57 & $1945-2002$ & 99 \\
\hline $\mathrm{S}_{\text {mass }}^{\text {reco-ishii }}$ & $\mathrm{S}_{\text {mass }}^{\text {reco-medar }}$ & 0.80 & 15.0 & 33 & $1970-2002$ & 99 \\
\hline$\partial \mathrm{M} / \partial \mathrm{t}^{\text {reco-ishii }}$ & $\partial \mathrm{M} / \partial \mathrm{t}^{\text {reco-medar }}$ & 0.71 & 1.4 & 32 & 1970-2002 & 99 \\
\hline$P_{\text {gpcp }}$ & $P_{\text {reofs }}$ & 0.41 & 4.9 & 23 & 1979-2001 & 95 \\
\hline$E_{\text {oaflux }}-P_{\text {gpcp }}$ & $\mathrm{E}_{\text {oaflux }}-\mathrm{P}_{\text {reofs }}$ & 0.67 & 5.0 & 23 & 1979-2001 & 99 \\
\hline
\end{tabular}

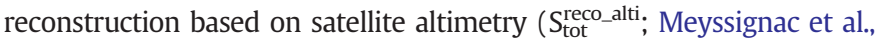
2011) one finds a good agreement with a correlation 0.95 and RMS differences $9 \mathrm{~mm}$ (see Table 2). The advantage of the MBMED11 reconstruction, compared to an alternative one by Calafat and Gomis (2009), is the use of the long-term sea level patterns deduced from a 33-year long run of the ARPERA-forced NEMOMED8 ocean model (Sevault et al., 2009) instead of a 13-year long altimetry record as in Calafat and Gomis (2009), which enables to better capture Mediterranean sea level decadal variability of specific interest to our study (Meyssignac et al., 2011).

We compute the steric component of sea level $\mathrm{S}_{\text {ster, }}$ taking into account both the effects of temperature $\left(S_{\text {thermo_ster }}\right)$ and salinity $\left(S_{\text {halo_ster }}\right)$. Temperature and salinity fields are obtained from two gridded climatologies: the regional Medar/Medatlas (Rixen et al., 2005; available yearly 1970-2002) and the global Ishii (Ishii and Kimoto, 2009; available monthly 1970-2006); and also from the MFSTEP oceanographic model (Tonani et al., 2008; 2002-2009). We integrate from the surface down to the maximum depth with available data (see Table 4). It is noted that models routinely provide potential temperature (Fofonoff, 1977), while climatologies give in-situ temperature; this is accounted for in our analysis concerning the estimation of steric heights.

We compute annual basin means of $S_{\text {ster, }} S_{\text {tot }}$, and their difference $S_{\text {mass }}$ to derive its rate of change $\partial \mathrm{M} / \partial \mathrm{t}$. The overlap between the GRACE-based mass estimate $S_{\text {mass }}^{g}$ and the indirect sea-level-based mass derivations (two separate ones from altimetry and reconstruction) over the common 2002-2009 period allows a comparison of the various methods as a mean to gain a sense of the uncertainties associated to the mass estimates (see Table 3 for comparisons; Calafat

Table 3

Correlation (Corr), root mean square difference (RMSD), number of samples (N) and level of significance of correlation (Significance) of observed and simulated annual time-series in 1979-2001 $(n=23)$.

\begin{tabular}{lllll}
\hline Simulated & Observed & Corr & $\begin{array}{l}\text { RMSD } \\
(\mathrm{mm} / \mathrm{mo})\end{array}$ & $\begin{array}{l}\text { Significance } \\
(\%)\end{array}$ \\
\hline $\mathrm{E}_{\text {protheus }}$ & $\mathrm{E}_{\text {oaflux }}$ & 0.50 & 4.2 & 99 \\
$\mathrm{P}_{\text {protheus }}$ & $\mathrm{P}_{\text {gpcp }}$ & 0.78 & 2.8 & 99 \\
$\mathrm{P}_{\text {protheus }}$ & $\mathrm{P}_{\text {reofs }}$ & 0.15 & 5.8 & 50 \\
$\mathrm{E}_{\text {protheus }}-\mathrm{P}_{\text {protheus }}$ & $\mathrm{E}_{\text {oaflux }}-\mathrm{P}_{\text {gpcp }}$ & 0.63 & 6.2 & 99 \\
$\mathrm{E}_{\text {protheus }}-\mathrm{P}_{\text {protheus }}$ & $\mathrm{E}_{\text {oaflux }}-\mathrm{P}_{\text {reofs }}$ & 0.46 & 5.6 & 95 \\
$\mathrm{G}_{\text {protheus }}$ & $\mathrm{E}_{\text {oaflux }}-\mathrm{P}_{\text {gpcp }}+\partial \mathrm{M} / \partial \mathrm{t}$ & 0.44 & 7.0 & 95 \\
$\mathrm{G}_{\text {protheus }}$ & $\mathrm{E}_{\text {oaflux }}-\mathrm{P}_{\text {reofs }}+\partial \mathrm{M} / \partial \mathrm{t}$ & 0.59 & 5.6 & 99 \\
$\mathrm{G}_{\text {protheus }}$ & $\mathrm{E}_{\text {oaflux }}-\mathrm{P}_{\text {reofs }}-\mathrm{R}-$ & 0.66 & 6.0 & 99 \\
& $\mathrm{~B}+\partial \mathrm{M} / \partial \mathrm{t}$ & & & \\
& & & &
\end{tabular}

Table 4

Annual errors of basin averages. Methods are RMS difference (RMSD) and error propagation $(\mathrm{EP})$ in $(\mathrm{mm})$ or $(\mathrm{mm} / \mathrm{mo})$ as indicated in Table 2 . Bold values have been selected to provide the final error estimate for $\mathrm{G}$ from $\mathrm{EP}$.

\begin{tabular}{|c|c|c|}
\hline & Annual error & Source \\
\hline$S_{\text {tot }}$ alti & 3 & RMSD of $S_{\text {tot }}$ alti \\
\hline$S_{\text {tot }}$ reco & 6 & EP, Meyssignac et al., 2011 \\
\hline \multirow[t]{2}{*}{$\mathrm{S}_{\text {tot }}$} & 4 & RMSD of $S_{\text {tot }}{ }^{\text {alti }}$ and $S_{\text {totl }}$ reco (Table 2) \\
\hline & 6 & Selected for EP \\
\hline \multirow[t]{3}{*}{$\mathrm{S}_{\text {ster }}$} & 12 & RMSD of $\mathrm{S}_{\text {ster }}$ \\
\hline & $15-25$ & $\mathrm{EP}$ \\
\hline & 15 & Selected for EP \\
\hline $\mathrm{S}_{\text {mass }}$ alti-ster & 12 & EP of $S_{\text {tot }}$ alti $\& S_{\text {ster }}$ \\
\hline $\mathrm{S}_{\text {mass }}$ reco-ster & 16 & EP of $S_{\text {tot }}{ }^{\text {reco }} \& S_{\text {ster }}$ \\
\hline $\mathrm{S}_{\text {mass }}$ & 15 & RMSD using various $\mathrm{S}_{\text {ster }}$ (Table 2 ) \\
\hline \multirow[t]{2}{*}{$\mathrm{S}_{\text {mass }}^{\mathrm{g}}$} & 7 & EP of GRACE \\
\hline & 16 & Selected for EP \\
\hline \multirow[t]{2}{*}{$\partial \mathrm{M} / \partial \mathrm{t}^{\text {reco-ster }}$} & 23 & EP of $S_{\text {mass }}$ reco-ster \\
\hline & 1.5 & RMS diff. of solutions (Table 2) \\
\hline \multirow[t]{2}{*}{$\partial \mathrm{M} / \partial \mathrm{t}^{\mathrm{g}}$} & 10 & EP of $S_{\text {mass }} g$ \\
\hline & 23 & Selected for EP \\
\hline \multirow[t]{3}{*}{$\mathrm{E}$} & $4.2-4.8$ & Yu et al., 2008 \\
\hline & 4 & RMSD of E datasets (Table 2) \\
\hline & 5 & Selected for EP \\
\hline \multirow[t]{3}{*}{$\mathrm{P}$} & $9-12$ & Adler et al., 2012 \\
\hline & 6 & RMSD of P datasets (Table 2) \\
\hline & 10 & Selected for EP \\
\hline \multirow[t]{3}{*}{ E-P } & 11 & $\mathrm{EP}$ \\
\hline & 6 & RMSD of E-P datasets (Tables 2,3) \\
\hline & 11 & Selected for EP \\
\hline $\mathrm{R}$ & 2 & STD of R \\
\hline B & 2 & STD of B \\
\hline \multirow[t]{3}{*}{ G } & 25 & EP including all components \\
\hline & 11 & EP of E-P, neglect $R, B, \partial M / \partial t$ \\
\hline & 7 & RMSD of results \\
\hline
\end{tabular}

et al., 2010; Fenoglio-Marc et al., 2012). It is worth noticing that over the common period, the GRACE mass change estimate (including both water and salt mass changes) is found to be largely similar to the indirect sea-level based derivation which only includes the effect of water mass changes in virtue of the steric correction (see Section 3.1). This suggests that, at least for this period, mass changes measured by GRACE were mostly water induced.

\subsection{Observational evaporation and precipitation data}

Both oceanic evaporation and precipitation are challenging quantities to derive, as neither is directly observed. Mariotti (2010) provides a recent intercomparison of estimates for the Mediterranean Sea from various datasets and methodologies over the period since the

Table 5

Standard deviation (STD), trend and its significance of observed and simulated water cycle parameters in 1979-2001.

\begin{tabular}{llll}
\hline & $\begin{array}{l}\text { STD } \\
(\mathrm{mm} / \mathrm{mo})\end{array}$ & $\begin{array}{l}\text { Trend } \\
(\mathrm{mm} / \mathrm{mo}) / \mathrm{yr}\end{array}$ & $\begin{array}{l}\text { Significance } \\
(\%)\end{array}$ \\
\hline $\mathrm{E}_{\text {protheus }}$ & 3.3 & $0.03+/-0.08$ & - \\
$\mathrm{P}_{\text {protheus }}$ & 4.1 & $-0.13+/-0.13$ & 75 \\
$\mathrm{R}_{\text {protheus }}$ & 2.0 & $-0.10+/-0.06$ & 90 \\
$\mathrm{~B}_{\text {protheus }}$ & 2.2 & $-0.00+/-0.06$ & - \\
$\mathrm{G}_{\text {protheus }}$ & 7.9 & $0.34+/-0.22$ & 90 \\
$(\mathrm{E}-\mathrm{P})_{\text {protheus }}$ & 5.7 & $0.15+/-0.14$ & 75 \\
$(\mathrm{R}+\mathrm{B})_{\text {protheus }}$ & 3.4 & $-0.10+/-0.11$ & 75 \\
$(\mathrm{E}-\mathrm{P}-\mathrm{R}-\mathrm{B})_{\text {protheus }}$ & 8.5 & $0.25+/-0.20$ & 75 \\
$\mathrm{E}_{\text {oaflux }}$ & 6.9 & $0.43+/-0.09$ & 99 \\
$\mathrm{P}_{\text {gpcp }}$ & 4.0 & $-0.31+/-0.13$ & 99 \\
$\mathrm{E}_{\text {oaflux }}-\mathrm{P}_{\text {gpcp }}$ & 8.2 & $0.74+/-0.13$ & 99 \\
$\mathrm{E}_{\text {oaflux }}-\mathrm{P}_{\text {gpcp }}-(\mathrm{R}+\mathrm{B})_{\text {protheus }}$ & 6.9 & $0.84+/-0.20$ & 99 \\
$\partial \mathrm{M} / \partial \mathrm{t}$ & 1.6 & $-0.09+/-0.13$ & 99 \\
$\mathrm{E}_{\text {oaflux }}-\mathrm{P}_{\text {gpcp }}-(\mathrm{R}+\mathrm{B})_{\text {protheus }}+\partial \mathrm{M} / \partial \mathrm{t}$ & 9.1 & $0.74+/-0.23$ & 99 \\
$\mathrm{E}_{\text {oaflux }}-\mathrm{P}_{\mathrm{gpcp}}+\partial \mathrm{M} / \partial \mathrm{t}$ & 8.4 & $0.66+/-0.14$ & 99 \\
\hline
\end{tabular}


late-1950s and allows qualitative insights into the uncertainties associated with Mediterranean Sea E and P estimates. In this study, we choose to use selected estimates of $\mathrm{E}$ and $\mathrm{P}$ among those analyzed by Mariotti (2010) rather than explore the full range of estimates available, while keeping in mind the range of uncertainties highlighted by the Mariotti (2010) study. For evaporation over the period 1958-2006, we use the derivation from the air-sea fluxes dataset OAFLUX, which objectively synthesizes surface meteorology obtained from satellite products (including SSM/I, Quick Scatterometer (QuikSCAT), Advanced Very High Resolution Radiometer (AVHRR), Tropical Rainfall Measuring Mission (TRMM)) and model NCEP re-analyses (Yu et al., 2008). For precipitation over 1979-2006, we consider data from the Global Precipitation Climatology Project (GPCP; Adler et al., 2003). Back in time, for the period 1960-2006 we use a reconstruction of oceanic precipitation (REOFS hereafter; Smith et al., 2008), which aims at capturing the large-scale features of global precipitation. Estimated OAFLUX evaporation error for the Mediterranean Sea is 4.2-4.8 mm/mo (5-6 $\mathrm{Wm}^{2}$ or more conservatively 5-8 $\mathrm{Wm}^{2}$; Yu et al., 2008). Estimated GPCP precipitation error is $9-12 \mathrm{~mm} / \mathrm{mon}$ for GPCP $(0.3-0.4 \mathrm{~mm} / \mathrm{d}$; Adler et al., 2012). No error estimate is available for REOFs (see Table 4 for intercomparison of error estimates).

\subsection{Climate model simulation}

We consider results from a regional ocean-atmosphere coupled model simulation with the PROTHEUS system (Artale et al., 2010). The PROTHEUS system includes the RegCM3 atmospheric regional model (Pal et al., 2007) and the MED-MITgcm ocean model (Marshall et al., 1997; Sannino et al., 2009b), that are coupled through the OASIS3 coupler (Valcke and Redler, 2006). It is a hydrostatic ocean model that uses the Boussinesq approximation (volume-conserving condition) (Song and Hou, 2006). As the volume of water in the model domain is conserved by model's construction the volume of water lost from the Mediterranean basin is balanced by means of a positive flux of water over the Atlantic box (see Carillo et al., 2012 for a complete validation of the ocean model). The experiment considered here is a simulation of climate variability in the European-Mediterranean domain over the period 1958-2001 at a spatial resolution of $30 \mathrm{~km}$ for the atmospheric component and $1 / 8^{\circ} \times 1 / 8^{\circ}$ for the oceanic model. The model includes the Interactive RIver Scheme (IRIS) that computes river discharge from runoff (Dell'Aquila et al., 2012). The oceanic and the atmospheric models exchange coupling fields (SST, wind stress components and total heat and salt fluxes) every $6 \mathrm{~h}$. Surface natural boundary conditions are used for the oceanic model which treats $\mathrm{P}+\mathrm{R}-\mathrm{E}$ as a real fresh water flux.

The ocean component is initialized with MEDATLAS II data (MEDAR Group, 2002), then a 40 year spin-up is performed using a $3 \mathrm{D}$ relaxation of temperature and salinity to the climatological values. ERA40 re-analyses (Uppala et al., 2005) are used as atmospheric lateral boundary conditions. The two-way exchange through the Strait of Gibraltar is achieved by means of 3D relaxation of salinity and temperature toward the climatological monthly Levitus data (Levitus, 1982), in a box composed by 30 grid points located west of Gibraltar. The PROTHEUS net water flux at Gibraltar is computed as the volume transport through a latitudinal section, derived as difference of the two-way exchange given in Fig. 3S.

Since observational estimates of $\mathrm{R}$ and $\mathrm{B}$ times series for the period 1970-2009 are not available, we consider R, B values from the PROTHEUS simulation as observational surrogates, to be used in the water budget equation (Eq. 1) to derive G, together with data from observational datasets. However the modeled terms are roughly an order of magnitude smaller than E (Mariotti et al., 2002), hence are second order factors in the estimation of G. Because of the different assumptions in the simulated $G$ versus the indirectly observationally derived $\mathrm{G}$, comparing the two allows to both corroborate independently derived
G estimates and also explore whether the model's condition is indeed a realistic assumption.

\subsection{Climatic indices}

We consider various climatic indices to explore the role of large-scale climate phenomena on long-term $G$ variability as it relates to other water cycle changes. Specifically, the December-March (DJFM) station-based NAO index calculated as the normalized pressure difference between Gibraltar and South West Iceland [Jones et al., 1997]; and the annual AMO index available from NOAA/OAR Physical Science Division calculated as the de-trended area-weighted average of North Atlantic $\left(0^{\circ}\right.$ to $\left.70^{\circ} \mathrm{N}\right)$ Sea Surface Temperature (SST) (available since 1856) (Enfield et al., 2001). To compare with the NAO index, we consider DJFM means of Mediterranean mean P, R and $\partial \mathrm{M} / \partial \mathrm{t}$, and compute six-years running means to focus on long-term variability. In this analysis, we also include monthly mean sea-level pressure from the HadSLP2 dataset (SLP), combining land and marine pressure observations (Allan and Ansell, 2006). In the comparison with the AMO index, we consider six-year running means of annual values. Annual mean anomalies are relative to the period 1979-2001, as this is the common period of availability for all data used.

\section{Results}

\subsection{Mediterranean Sea mass variability}

Fig. 1 shows anomalies of annual mean basin-averaged sea-level in 1970-2009, as derived from the altimeter measurements $\left(S_{\text {tot }}^{\text {alti }}\right)$ and the sea-level reconstruction $\left(S_{\text {tot }}^{\text {reco }}\right)$. Over the 1970-2005 period, reconstructed sea-level displays both interannual and decadal variations with relative minima observed around 1975 and 1994. The monthly error associated with the reconstructed basin-averaged sea-level estimated by a bootstrap method (Efron and Tibshirani, 1993) is about $20 \mathrm{~mm}$ and significant at the 95\% level (see Meyssignac et al., 2011 for more details). The corresponding annual mean error is $6 \mathrm{~mm}$. The annual mean error of the altimetric basin-averaged sea level is $3 \mathrm{~mm}$ based on a RMS difference between data sets (Table 4, see also Fenoglio-Marc et al., 2012). Overall, there is very good consistency for basin averaged sea-level between the altimeter estimates and the reconstructed estimates, which reinforces confidence in the sea-level reconstruction for the earlier period. Over the common interval 1993-2005, yearly mean sea-level estimates from the reconstruction and from the altimeter observations are in good agreement with a 0.98 correlation and $4 \mathrm{~mm}$ RMS difference (Tables 2, 4). We finally assume a value of $6 \mathrm{~mm}$ for the error of the combined sea level $S_{\text {tot }}$, to account for the lower accuracy of the

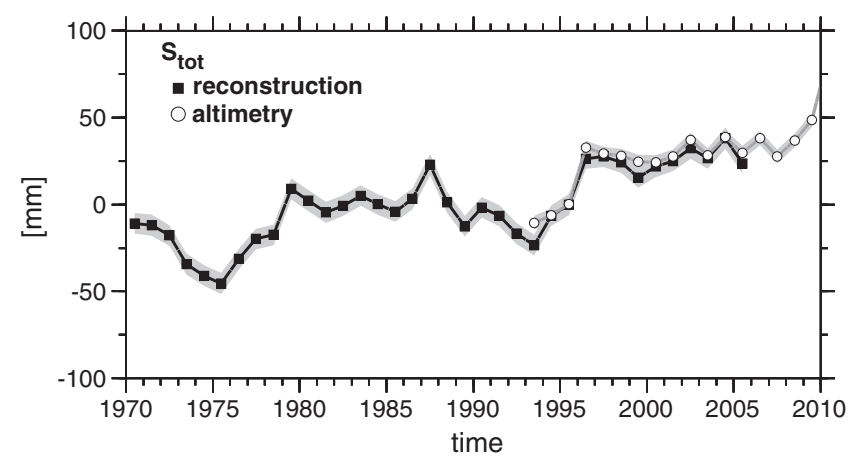

Fig. 1. Yearly mean sea level anomaly in the Mediterranean Sea over the period 1970-2009 derived from multi-satellite altimetry (circle) and from MBMED11 reconstruction (square) with error bounds corresponding both to the RMS difference of input data (gray shadow). 
reconstruction before the altimeter era (Table 4). The overall trend of the combined sea level $\mathrm{S}_{\text {tot }}$ over $1970-2009$ is $1.9+/-0.2 \mathrm{~mm} / \mathrm{yr}$.

Fig. 2 shows the annual basin average anomalies of the steric component $\left(\mathrm{S}_{\text {ster }}\right)$ derived from the Medar/Medatlas and from the Ishii gridded climatologies. Over the common interval 1945-2002 correlation and RMS difference between the two derivations are 0.57 and $12 \mathrm{~mm}$, with correlation significant at the 99\% level (Table 2). The RMS difference mainly arises from the difference in halo-steric components, which are still significantly correlated at the 99\% level (correlation and RMS difference of 0.36 and $12 \mathrm{~mm}$, respectively). The thermo-steric components $\left(\mathrm{S}_{\text {thermo-ster }}\right)$ are more similar (correlation and RMS difference are 0.81 and $5 \mathrm{~mm}$ respectively). These differences can be partly attributed to the different depths covered by the Ishii and Medar/Medatlas datasets (maximum depths available are $700 \mathrm{~m}$ and $4000 \mathrm{~m}$ respectively) and partly attributed to the different values of temperature and salinity in the databases. As results do not change significantly when integrating Medar/Medatlas to $600 \mathrm{~m}$ only (see Fig. 2) we may conclude that this second reason holds.

The RMS-based error of $12 \mathrm{~mm}$ derived above is our first estimate of the error of the steric component (Table 4). Another estimate is obtained from the grid of statistical errors associated to each Medar/ Medatlas grid (Rixen et al., 2005). The error of the basin average of temperature $(\mathrm{T})$ and salinity $(\mathrm{S})$ for different intervals in depths has been computed from the grid of statistical errors. The error associated with the specific volume has been evaluated as:

$\varepsilon(\alpha)=\left|\frac{\partial \alpha(S . T . P .)}{\partial S}\right| \varepsilon(S)+\left|\frac{\partial \alpha(S . T . P .)}{\partial T}\right| \varepsilon(T)$

where $\varepsilon(T)$ and $\varepsilon(S)$ are the objective analysis errors associated to $T$ and $S$ and are function of time and space. A Monte-Carlo approach is used to perturb $\varepsilon(T)$ and $\varepsilon(S)$ so as to obtain the associated specific volume anomaly. The gridded temperature and salinity fields were perturbed

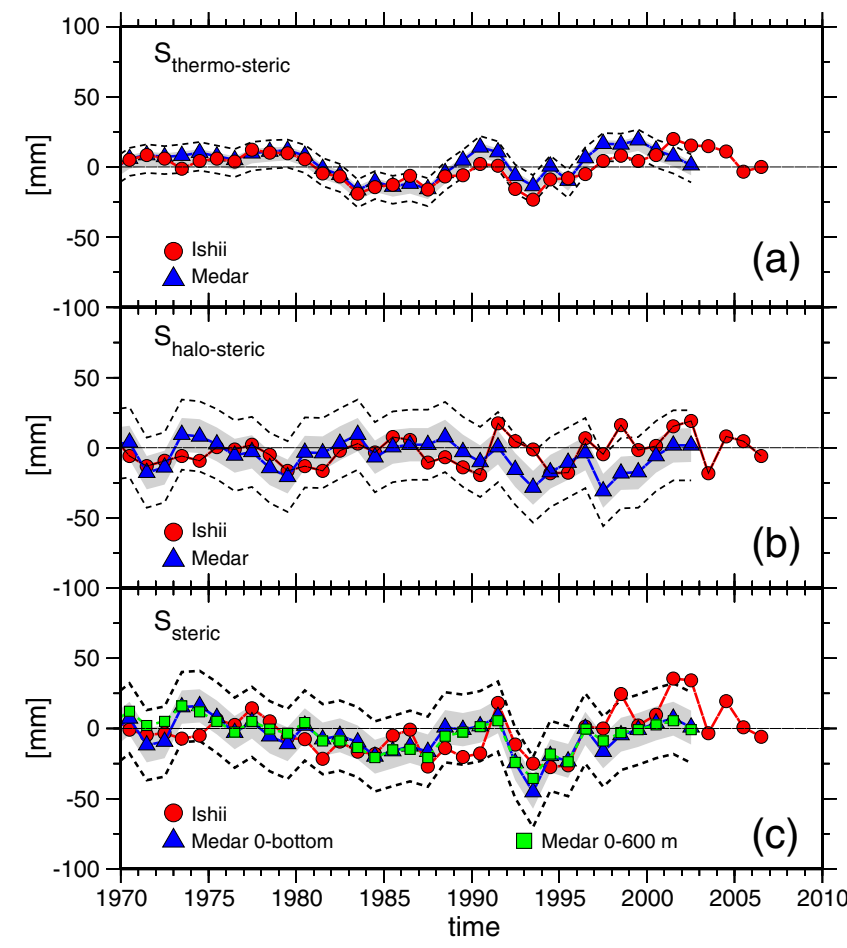

Fig. 2. Yearly mean thermo-steric (a), halo-steric (b), total steric (c) sea level anomalies in the Mediterranean Sea over the period 1970-2006 from Ishii version 6.7 (circle) and Medar/Medatlas integrated until 4000 meter depth (triangle). In c) Medar/Medatlas integrated until 600 (square) is shown in addition. Error bounds computed from Medar/ Medatlas (dashed line) and corresponding both to the RMS difference of input data (gray shadow) are given. within the range of its associated temperature and/or salinity uncertainty so as to infer total, thermo and halosteric uncertainty; 100 members were sufficient to make the algorithm converge. Steric anomalies were directly confronted to the unperturbed reference.

Fig. 1S (additional material) shows basin averages of temperature and salinity data averaged over different intervals of depths together with the corresponding uncertainty. Being the variability range of temperature and salinity higher at the surface than at depth, and despite the lower amount of data at deeper levels, the uncertainty of the data decreases with depth. The uncertainties of the basin averages are between 0.1 and $0.2{ }^{\circ} \mathrm{C}$ in the first $150 \mathrm{~m}$ and lower than $0.1{ }^{\circ} \mathrm{C}$ below $150 \mathrm{~m}$. Uncertainties are higher at both ends of the 1945-2002 period due to the lower amount of observations available to the objective analysis.

The volume uncertainty derived from a Monte Carlo perturbation of temperature and/or salinity for year 1995 (3-year running window) is illustrated in Fig. 2S. The steric uncertainty contributions are mainly located in deep ocean basins, as uncertainties are then integrated over larger depths. The halo-steric uncertainties dominate and reach $10 \mathrm{~mm}$ in the top $600 \mathrm{~m}$ and $15-25 \mathrm{~mm}$ in the complete water column (Table 4). This is mainly due to the scarcity of salinity data in the (eastern) Mediterranean. Results for other years in the 1960-1995 period are qualitatively similar. In summary, results suggest that the total steric anomaly uncertainties are lower than $25 \mathrm{~mm}$ for the whole water column. The uncertainty is lower near to the surface and is less than $5 \mathrm{~mm}$ for the $0-150 \mathrm{~m}$ layer, less than $10 \mathrm{~mm}$ for the $150-600 \mathrm{~m}$ layer and less than $15 \mathrm{~mm}$ for the $600-4000$ m layer. It is however well known that theoretical errors provided by the objective analysis techniques usually underestimates actual errors, therefore errors could be higher. We observe that the error estimated for Medar/Medatlas is larger than the error derived for RMS difference of data. We finally assume a value of $15 \mathrm{~mm}$ for the error of the combined steric sea level $\mathrm{S}_{\text {ster }}$ (Table 4). The two different estimates of the steric component are quite consistent (Fig. 2, c). They show a tendency for the steric component to decrease from 1970 until the mid-1990s and increase thereafter (considering Ishii data, trends are $-1.02+/-0.34 \mathrm{~mm} / \mathrm{yr}$ during $1970-1990$ and $1.19+/-0.8 \mathrm{~mm} / \mathrm{yr}$ during 1990-2006).

As described in previous section, the steric component of basin-averaged sea level (as shown in Fig. 2) is used in combination with basin-averaged sea-level estimates (as shown in Fig. 1) to derive basin-averaged Mediterranean water mass variations $S_{\text {mass. }}$ Fig. 3 shows annual mean basin-average Mediterranean Sea water mass anomalies over the period 1970-2009 based on the multiple sea-level and steric components estimates described above. Overall the various estimates depict a quite consistent behavior during the periods for which the data overlap both on interannual and longer timescales. Specifically, the correlation and RMS differences between the mass derivations considering the two different steric corrections of the sea-level reconstruction are 0.8 and $15 \mathrm{~mm}$, respectively, with correlation statistically significant at the $99 \%$ confidence level (Table 2). Nevertheless there are differences among these estimates, highest differences are found in mid-1970s and early 1990s, which are however within the error bars based on Fig. 2 .

Mass estimates from the Ishii steric-corrected sea-level reconstruction and the Ishii steric-corrected altimetry values are in particularly good agreement during 1993-2006. Similarly there is very good agreement between the mass estimates from the MFSTEP steric-corrected altimetry and the direct mass retrievals from GRACE for the most recent period (Fig. 3). As previously mentioned, the agreement between GRACE and the steric-corrected reconstructions during the period of overlap suggests that the mass changes measured by GRACE are primarily water mass induced. Relative minima occur in the mid-1970s, the early 1990s and early in the 2000s. Over the long-term, considering the period since 1970s, Mediterranean Sea water mass is seen to increase (this is consistent with 

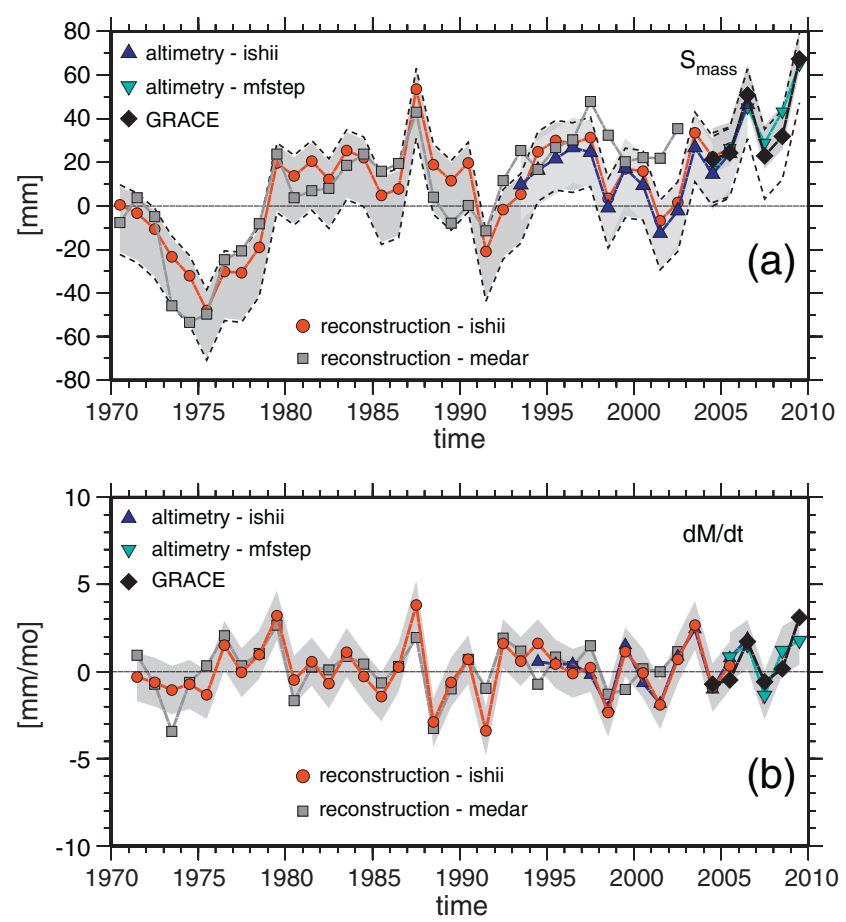

Fig. 3. Yearly mass-induced sea level anomaly in Mediterranean Sea (a) and its time derivative (b) over the period 1970-2009. Shown are estimates based on the steric-corrected sea-level reconstruction using two different steric corrections (squares for Medar/ Medatlas and circles for Ishii), on the steric-corrected sea-level altimetry using two different steric corrections (inverted triangles from MFSTEP and triangles from Ishii) and on GRACE-based mass retrievals (diamonds). Bounds in (a) correspond both to error propagation of components (dashed line) and to RMS difference of solutions derived from input data in Figs. 1 and 2 (gray shadow). In (b) only bounds corresponding to RMS of solutions are shown.

Calafat et al., 2010). The trend over the period 1970-2006 is $0.88+/-0.33 \mathrm{~mm} / \mathrm{yr}$ based on the reconstruction corrected for the Ishii steric component. Considering the extended time series (1970-2009), that combines the reconstruction- and the GRACEbased $\mathrm{S}_{\text {mass }}$, the trend is $1.1+/-0.3 \mathrm{~mm} / \mathrm{yr}$.

The estimate of the annual error of the mass-induced sea-level $\mathrm{S}_{\text {mass, }}$ derived by error propagation from the errors of $S_{\text {tot }}$ and $S_{\text {ster }}$ is $16 \mathrm{~mm}$ (dashed line in Fig. 3a), in very good agreement with the above obtained RMS difference-based error of $15 \mathrm{~mm}$ (shaded bounds in Fig. 3.a). The annual error of GRACE-derived mass-induced sea-level $S_{\text {mass }}$ is smaller ( $7 \mathrm{~mm}$, see also Fenoglio-Marc et al., 2012). We finally assume a value of $16 \mathrm{~mm}$ for the annual error of the combined mass-induced sea-level $S_{\text {mass }}$ over 1970-2009 (Table 4).

Finally, the annual mean water mass change $\partial \mathrm{M} / \partial \mathrm{t}$ (the term that actually enters Eq. 1) is derived over 1970-2009 as the difference of the combined mass-induced sea level $S_{\text {mass }}$ at two following time steps (Fig. 3b). The timeseries shows interannual $\partial \mathrm{M} / \partial \mathrm{t}$ values of up to $3-4 \mathrm{~mm} / \mathrm{mo}$, its standard deviation is $1.8 \mathrm{~mm}(1.6 \mathrm{~mm}$ in 1979-2001, see Table 5). The overall $\partial \mathrm{M} / \partial \mathrm{t}$ mean is $0.14 \mathrm{~mm} / \mathrm{mo}$ as there is an overall mass increase over the period of consideration. However there is no significant $\partial \mathrm{M} / \partial \mathrm{t}$ trend over the period of consideration (trend value for the $\partial \mathrm{M} / \partial \mathrm{t}$ based on mass estimates from the reconstruction and Ishii steric correction is $0.018+/-0.024 \mathrm{~mm} / \mathrm{mo}$ per year). It is interesting to note that $\partial \mathrm{M} / \partial \mathrm{t}$ is small, as it is indeed often assumed to be according to the "equilibrium condition"; hence based on the water budget equation (Eq. 1) we find a first order compensation between $G$ and other terms of Mediterranean Sea water cycle, primarily $\mathrm{E}$ and $\mathrm{P}$ (another common assumption).

We obtain for $\partial \mathrm{M} / \partial \mathrm{t}$ an annual error of $23 \mathrm{~mm}$, from error propagation of $S_{\text {mass. }}$. The annual error of the GRACE-based mass-induced sea-level $\partial \mathrm{M} / \partial \mathrm{t}$ is smaller $(10 \mathrm{~mm})$. Also the RMS difference of the various estimates of $\partial \mathrm{M} / \partial \mathrm{t}$ derived from various sea-level and steric data is significantly smaller $(1.5 \mathrm{~mm})$ (Table 4$)$. The standard deviation of $\partial \mathrm{M} / \partial \mathrm{t}$ is $1.6 \mathrm{~mm}$ and therefore much smaller than its error.

\subsection{Gibraltar water flux variability}

Next, remaining Mediterranean Sea water cycle terms are considered in order to close the water budget (Eq. 1) and derive $G$ variability over the period 1960-2010 (see Fig. 4; see Tables 2,3 for correlation and RMS difference of the yearly time-series and Table 5 for a comparison of observed and simulated trends over the period). Both observational and PROTHEUS-simulated estimated annual mean anomalies relative to the period 1979-2001 are considered for comparison (as available). Note that the PROTHEUS simulation is forced at the atmospheric boundaries by ERA40 reanalyses, independent from the observational estimates presented here. Mediterranean Sea averaged evaporation from OAFLUX data shows an initial decrease 1960 to the mid-1970s, followed by an increase up until the most recent period (trend over 1979-2001 is $0.43+/-0.09 \mathrm{~mm} / \mathrm{mo}$ per year; see Mariotti, 2010 for more discussion on decadal variability of Mediterranean Sea evaporation). PROTHEUS-simulated evaporation shows a similar decadal variability over the whole period, with basically no increase during 1979-2001 (Fig. 4.a)

GPCP precipitation shows a negative trend over the period 1979-2001 $(-0.31+/-0.13 \mathrm{~mm} / \mathrm{mo}$ per year $)$, similarly to the

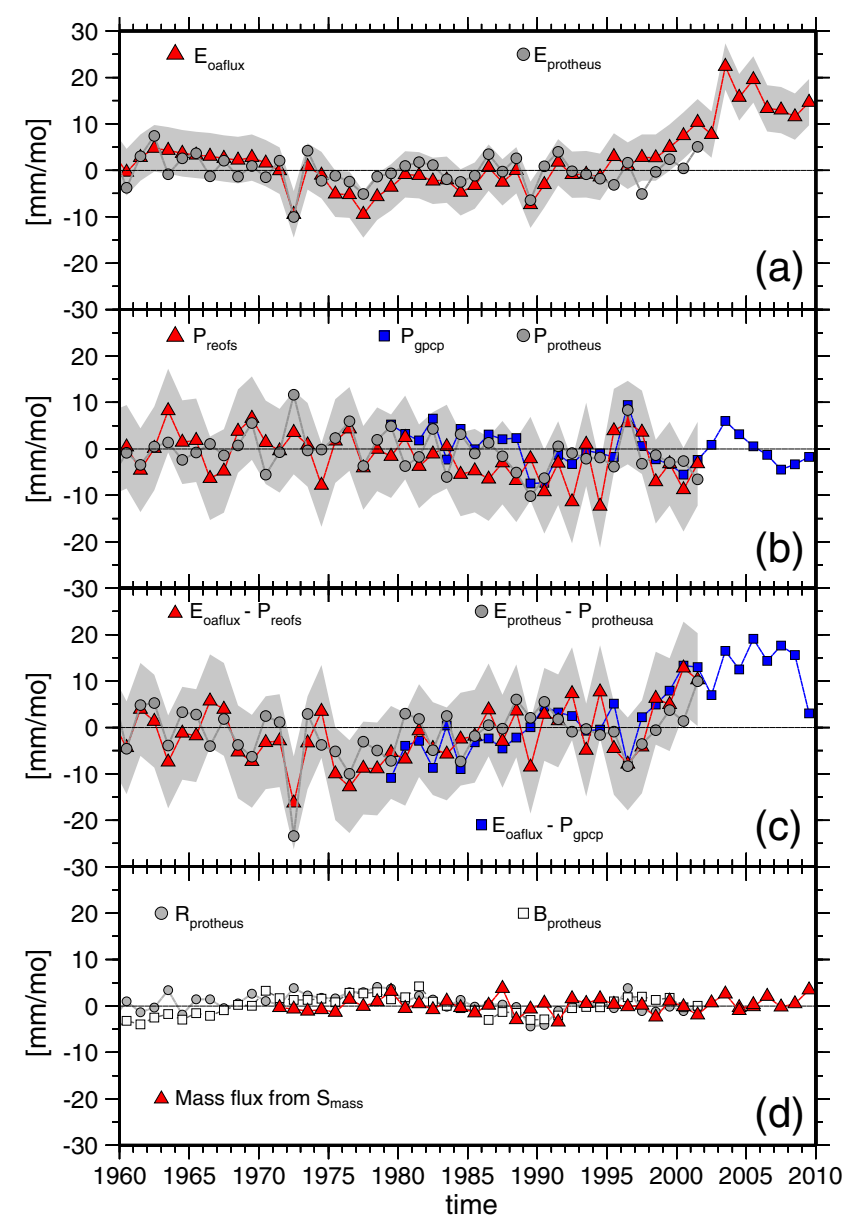

Fig. 4. Yearly anomalies of Mediterranean Sea water cycle components in water budget equation (Eq. 1) during 1960-2009 relative to the period 1979-2001. From top to bottom: Evaporation (a), Precipitation (b), E-P (c), Bosphorus water flux, river discharge and time derivative of mass-induced sea level (Fig. 3b) (d) from model simulations (gray) and observations. Legend specifies data source. Error bounds in (a-b-c) correspond to the RMS difference of data input from databases (gray shadow). 
PROTHEUS-simulated one except the latter is smaller and weakly significant (Fig. 4.b). REOF reconstruction also shows a precipitation decrease during 1979-2001 that is similar to GPCP but in the context of a long-term decrease during the period since 1960 (see also Mariotti, 2010). Correlation and RMS difference of the GPCP and REOF precipitation yearly values are 0.4 and $4.9 \mathrm{~mm} / \mathrm{mo}$ respectively, correlation is significant at the $95 \%$ level (Table 2). The correlation of simulated and observed evaporation and precipitation quantities are all significant, except for precipitation from REOFS (Table 3). Their RMS differences are $4 \mathrm{~mm} / \mathrm{mo}$ for evaporation and $6 \mathrm{~mm} / \mathrm{mo}$ for precipitation (Table 3); we adopt these values as the RMS-based errors for the two quantities (see Table 4). We finally assume an error of $5 \mathrm{~mm} / \mathrm{mo}$ and $10 \mathrm{~mm} / \mathrm{mo}$ for the two quantities, thus error propagation gives a result of $11 \mathrm{~mm} / \mathrm{mo}$ for E-P.

Based on the observational estimates, the combination of the evaporation increase seen in OAFLUX data and precipitation decrease seen in GPCP gives a significant increase in net evaporation (E-P) over the period 1979-2001 (Fig. 4.c). Observationally derived trend over 1979-2001 is $0.74+/-0.13 \mathrm{~mm} / \mathrm{mo}$ per year. Simulated net evaporation trend is also seen to be positive, albeit weakly significant. The GPCP/OAFLUX E-P estimates indicate that the increase has been continuing up until the recent period (trend over $1979-2009$ is $0.79+/-0.1 \mathrm{~mm} / \mathrm{mo}$ per year). Error propagation gives a result of $11 \mathrm{~mm} / \mathrm{mo}$ for E-P (Table 4), while the RMS-based error computed from various datasets is lower than $6.2 \mathrm{~mm} / \mathrm{mo}$ (Tables 2, 3).

Since observational river discharge and Bosphorus water flux anomalies are not available for the period of investigation, we consider the simulated quantities as a surrogate (in any case, as previously discussed these are second order terms in Eq. 1). Simulated river discharge shows a significant negative trend over 1979-2001 $(-0.1+/-0.06 \mathrm{~mm} / \mathrm{mo}$ per year; Table 5), consistent with simulated precipitation behavior. Simulated water flux at the Bosphorus Strait does not indicate a significant trend. Relying on a single run of a single model we cannot attribute an error bar to such estimate, however this fact does not impair our results, as the river runoff is, together with the Bosphorus the smallest term in Eq. (1) and does not exceed the $20 \%$ of the E-P budget (Mariotti et al., 2002). This relationship holds also in our analysis (see Table 5 ) between the standard deviations of the R and B simulated time-series ( 2 and 2.2 respectively) and of E-P observed ( $8.2 \mathrm{~mm} / \mathrm{mon}$ ) and simulated $(5.7 \mathrm{~mm} / \mathrm{mo}$ ) (Table 5$)$. A similar relationship holds for the rate of mass change $\partial \mathrm{M} / \partial \mathrm{t}$ (Fig. 4.d), as the standard deviation of $\partial \mathrm{M} / \partial \mathrm{t}$ is $1.6 \mathrm{~mm} / \mathrm{mo}$ (Table 5 ) and therefore smaller than for all the other components in Eq. (1).

Combining observational $\mathrm{E}$ and $\mathrm{P}$ estimates with simulated $\mathrm{R}$ and $\mathrm{B}$, we obtain estimates of the overall mean fresh water budget anomalies that have characterized the Mediterranean Sea over 1979-2001. Interannual anomalies are of the order of $5-10 \mathrm{~mm} / \mathrm{mo}$ with a linear trend over $1979-2001$ of $0.84+/-0.20 \mathrm{~mm} / \mathrm{mo}$ per year (this trend value is based on GPCP precipitation, OAFLUX evaporation and simulated $\mathrm{R}$ and $\mathrm{B}$ ), that is a linear increase of about $19 \mathrm{~mm} / \mathrm{mo}$ in total over this period. The corresponding simulated fresh water budget quantity also shows an increase, however trend value is smaller than observed $(0.25+/-0.20 \mathrm{~mm} / \mathrm{mo}$ per year or about $6 \mathrm{~mm} / \mathrm{mo}$ in total over this period). Error propagation gives an error of $11 \mathrm{~mm} / \mathrm{mo}$ for E-P-R-B, if we neglect the errors of $\mathrm{R}$ and $\mathrm{B}$. If we assume for $\mathrm{R}$ and $\mathrm{B}$ an error equal to their standard deviation ( $2 \mathrm{~mm} / \mathrm{mo}$, Table 4 ), the resulting error is not significantly different.

Finally, we combine the fresh water budget changes discussed above with mass changes $\partial \mathrm{M} / \partial \mathrm{t}$ as derived in the previous section to depict Gibraltar water flux (G) variability during 1960-2009 based on the application of the water budget equation (Eq. 1) (see Fig. 5).

All G estimates, whether combining observational and PROTHEUSsimulated terms or derived purely from the PROTHEUS simulation, show an overall increase in the net water flux at Gibraltar since the mid-1970s. It is worth underlying that a priori the observationally derived $G$ and the PROTHEUS simulated $G$ could be quite different, because of the assumptions built-in the model, in primis the "equilibrium condition" assumption. The best agreement with the model is obtained when all components of Eq. (1) are included (correlation and RMS difference are 0.66 and $6 \mathrm{~mm}$, see Table 3 ); neglecting $\mathrm{R}$ and $\mathrm{B}$, the correlation drops to 0.59 , with significance level still $99 \%$. If one neglects $R$ and $B$, and derives $G$ purely based on observations (using estimated $\partial \mathrm{M} / \partial \mathrm{t}$, OAFLUX evaporation and precipitation from either GPCP or REOFs), one still finds an increase in G since the mid-1970s that is consistent with the PROTHEUS simulated G estimate. Based on the combined observational/modeling approach we find for G a linear trend over the period 1979-2001 of $0.74+/-$ $0.23 \mathrm{~mm} / \mathrm{mo}$ per year (see Table 5), that is a linear increase of about $16 \mathrm{~mm} / \mathrm{mo}$ over this period. The linear trend is even higher $(0.80+/-0.21 \mathrm{~mm} / \mathrm{mo}$ per year $)$ when the recent years are included (period 1970-2009) even neglecting the contribution of $\mathrm{R}$ and $\mathrm{B}$.

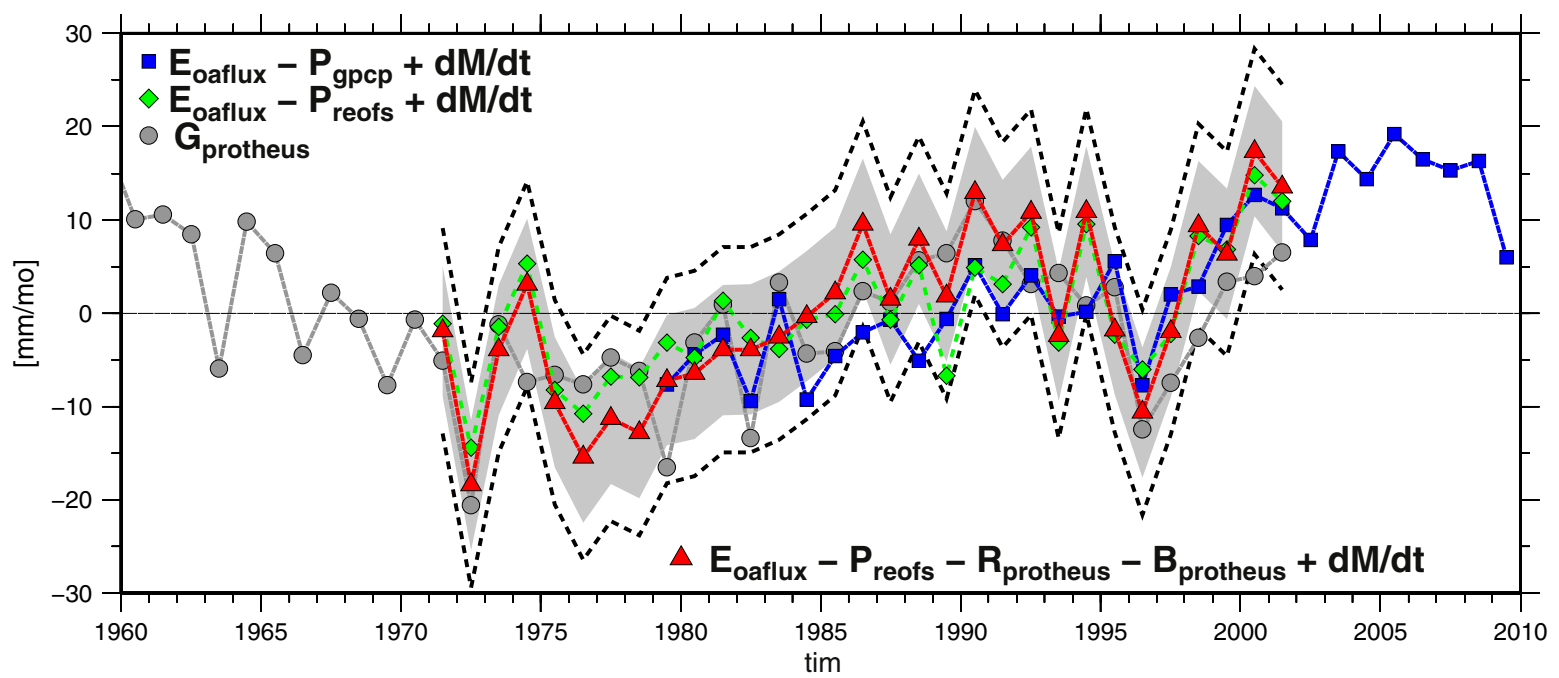

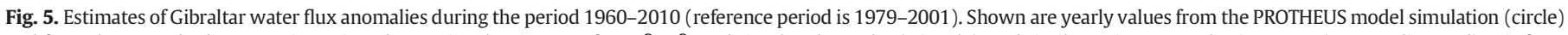

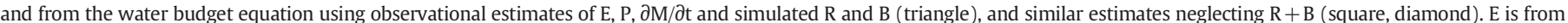

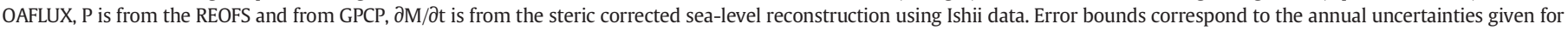

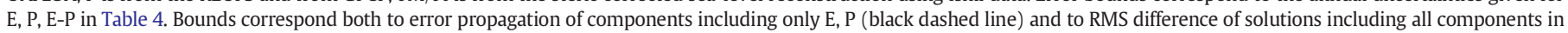
Fig. 4 (gray shadow). 
Simulated $G$ values give similar qualitative results, however with a $50 \%$ smaller trend $(0.34+/-0.22 \mathrm{~mm} / \mathrm{mo}$ per year or about $8 \mathrm{~mm} /$ mo over 1979-2001, see Table 5). Over the longer 1960-2000 period, the simulation indicates that the above mentioned $\mathrm{G}$ increase is in the context of broader decadal variations, with a decrease during 19601970 before the most recent increase; a similar result is found considering observational $G$ estimates (based on REOFS P, OAFLUX E and $\partial \mathrm{M} / \partial \mathrm{t}$, but neglecting $\mathrm{B}$ and $\mathrm{R}$ ). This variability is seen to have been primarily forced by precipitation and evaporation over the Mediterranean Sea, as variations in mass in the basin have been found to be comparatively small (consistently with previous knowledge). Results suggest that the increase in the fresh water loss at the sea-surface, as also found by Mariotti (2010), is compensated mainly by an increase in water fluxes at Gibraltar, with little change in $\partial \mathrm{M} / \partial \mathrm{t}$. As previously noted, this is an assumption built-in the PROTHEUS model (as in most state-of-art Mediterranean Sea models), which we find a posteriori to be well verified by the observational $\partial \mathrm{M} / \partial \mathrm{t}$ estimates.

The accuracy of the Gibraltar Strait flow is almost independent from the accuracy of the rate of change of mass in the basin, river runoff and the Bosphorus strait flow, as their magnitude is small when compared to the effect of evaporation and precipitation on the resulting Gibraltar net flux. The error estimate of $\mathrm{G}$, derived by error propagation from each component in Table 4, is $25 \mathrm{~mm}$. This value is 3 times larger than the RMS difference ( $7 \mathrm{~mm}$ ) of the various solutions obtained for $\mathrm{G}$ from the available data and models. For a realistic error estimate only the errors in $\mathrm{E}$ and $\mathrm{P}$ are considered and give an error of $11 \mathrm{~mm} / \mathrm{mo}$ for the Gibraltar Strait flow.

\subsection{Large-scale influences}

In order to gain some insights on the mechanisms driving the long-term Gibraltar water flux changes described above, we explore
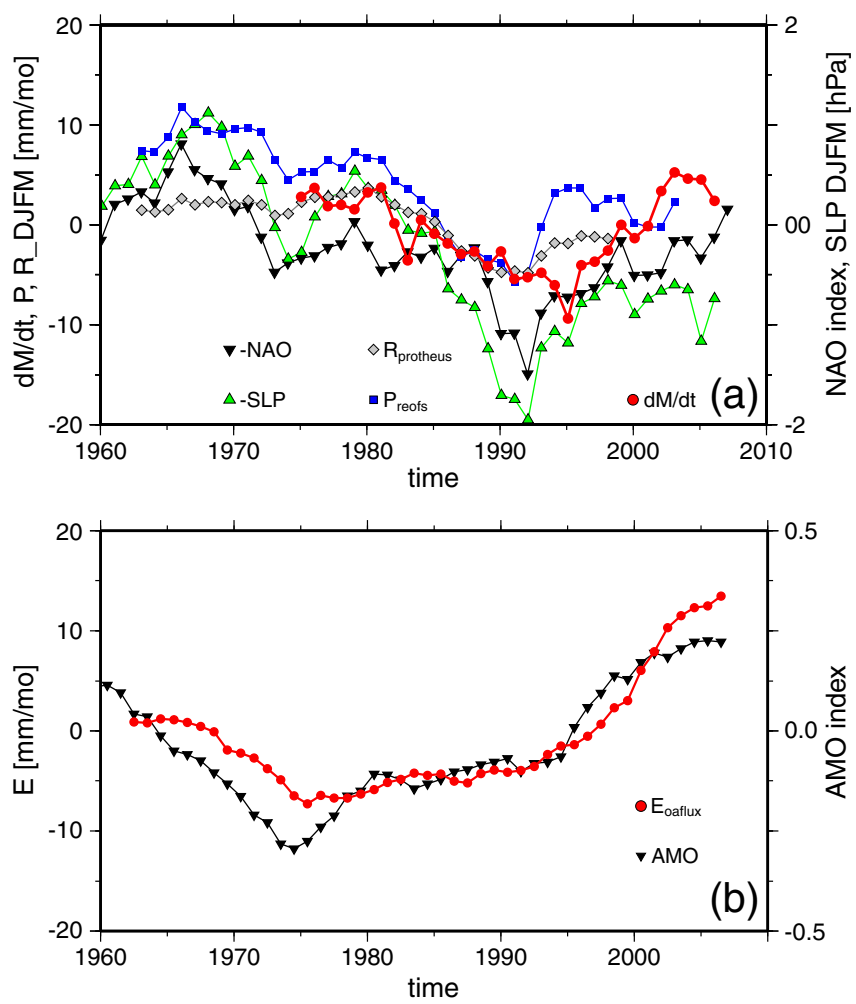

Fig. 6. Influence of large-scale climate modes on Mediterranean water mass budget components. DJFM yearly values of NAO index and anomalies of P, R sea level pressure, $\partial \mathrm{M} / \partial \mathrm{t}$ (note: the signs of the NAO and SLP are reversed) (top panel) and yearly values of the AMO index and of OAFLUX evaporation anomalies (bottom panel). For all, a six-year running mean is shown to focus on long-term anomalies.
Table 6

Correlation and significance of climatic index with variables in 1970-2006. For sea level the component type is indicated by the subscript (tot: total sea level; ster: steric sea level; thermo-ster: thermo-steric sea level; halo-ster: halo-steric sea level; mass: mass induced sea level).

\begin{tabular}{|c|c|c|c|}
\hline Climatic index & Field & Correlation & Significance (\%) \\
\hline $\mathrm{NAO}_{\text {DJFM }}$ & $\partial \mathrm{M} / \partial \mathrm{t}$ & 0.64 & 99 \\
\hline $\mathrm{NAO}_{\mathrm{DJFM}}$ & SLP (HadSLP) & 0.81 & 99 \\
\hline $\mathrm{NAO}_{\text {DJFM }}$ & $P_{\text {reofs }}$ & -0.70 & 99 \\
\hline $\mathrm{NAO}_{\mathrm{DJFM}}$ & $R_{\text {protheus }}$ & -0.77 & 99 \\
\hline AMO & $\mathrm{E}_{\text {oaflux }}$ & 0.9 & 99 \\
\hline
\end{tabular}

the relationship with major large-scale climate phenomena known to have had significant influence on decadal climate variability over the Mediterranean region (Mariotti and Dell'Aquila, 2012). Fig. 6a shows the DJFM means of the NAO index $\left(\mathrm{NAO}_{\mathrm{DJFM}}\right)$ and Mediterranean mean P, R and sea level pressure (SLP), with a 6-year moving average applied (see Table 6 for correlation values among the various time-series). Consistently with previous studies, the NAO shows a significant negative correlation with regional precipitation $(-0.70$ based on REOFS). In addition we also find a significant negative correlation with regionally averaged simulated river-discharge $(-0.77$; as also shown by Struglia et al. (2004), based on observational river discharge). All correlations are significant at the 99\% level. Observed NAO variability during $1960-2009$, with a well-known long-term increase during the 1960s to the early 1990s (Hurrell, 1995), has resulted in a precipitation and river discharge decrease during winter with an overall effect on annual means of these water cycle quantities. This in turn has contributed to increase the Mediterranean Sea fresh water budget (E-P-R) and related water fluxes at Gibraltar based on results from this work.

Previous studies have suggested the NAO also impacts Mediterranean sea-level owing to the inverse barometer effect (IB) (e.g. as described by Tsimplis and Josey, 2001). However in our study the altimeter data have been corrected for direct atmospheric effects including the IB and the PROTHEUS model does not simulate the effect of pressure. Therefore the effects of the NAO through local pressure have been removed and should not impact estimated mass changes and Gibraltar fluxes. However, for DJFM, we find an anti-correlation between the NAO index and regionally averaged sea level pressure SLP $(-0.81)$ and also a significant anti-correlation between the NAO and Mediterranean rate of mass change $\partial \mathrm{M} / \partial \mathrm{t}(-0.64)$. These results suggests that the NAO may affect the mass component of sea level $S_{\text {mass }}$ through mechanisms associated to redistribution of water, other than the atmospheric pressure changes. Those mechanisms could be associated to winds near the Gibraltar strait (Menemenlis et al., 2007) and to ocean circulation. However, these hypotheses need to be substantiated by targeted process studies.

Recent studies have shown a significant connection between Mediterranean Sea SST and the AMO, as well a connection between regional surface air temperature and the AMO particularly during the summer season (Marullo et al., 2011; Mariotti and Dell'Aquila, 2012). Because of the impact temperature can have on the humidity gradient and sea surface evaporation, we investigate the linkage between the AMO and Mediterranean Sea evaporation variability. Fig. 6b, shows 6-years running means of OAFLUX annual Mediterranean Sea evaporation anomalies together with those of the AMO index. We find significant positive correlation between evaporation and the AMO (0.9) which is consistent with the thermodynamical linkage hypothesized above. Again, this speculated connection needs to be investigated by further studies using different evaporation datasets and in-depth analyses of the thermodynamic changes associated with AMO variability in the Mediterranean. If confirmed, our study suggests that the impact of AMO variability on Mediterranean Sea is not only confined to Mediterranean SST (as also suggested 
by Mariotti and Dell'Aquila, 2012) but also affects the sea more broadly with evaporation-driven changes in Gibraltar water fluxes.

\section{Conclusions}

We have explored the long-term variability of net water flux into the Mediterranean Sea at the Gibraltar Strait over the period 1960-2009 based on an approach combining multiple observational datasets and results from a regional climate model simulation. The approach includes deriving Gibraltar water fluxes from the application of the full Mediterranean Sea water budget equation using observationally based estimates of mass variation (from GRACE satellite and indirect derivations from steric-corrected sea level changes from altimetry and a sea-level reconstruction), evaporation, precipitation and simulated river discharge and Bosphorus Strait water fluxes. This derivation is compared with results from a simulation using the PROTHEUS regional ocean-atmosphere coupled model considering both individual water cycle terms and overall Gibraltar water flux.

Based on observational estimates of Mediterranean Sea mass, we find that its changes are relatively small compared to water fluxes at the sea surface and with no long-term trend over 1970-2009. Hence, the "equilibrium condition" assumption, common to many Mediterranean Sea models is indeed a reasonable one. As a result, decadal variations in net evaporation (E-P) at the sea-surface drive changes in net inflow at Gibraltar as dictated by the water budget equation, while changes in river runoff and net inflow at the Bosphorus Strait have a secondary modulating effect. Estimates from this approach have been compared to the PROTHEUS simulated Gibraltar Strait water fluxes over the period 1960-2001. Results from both methodologies point to an increase in net water flux at Gibraltar over the period $1970-2009(0.8+/-0.2 \mathrm{~mm} / \mathrm{mo}$ per year based on the observational approach) primarily resulting from an increase in evaporation and a decrease in precipitation during this period. Above mentioned G increase over 1970-2009 is in the context of broader decadal including a net Gibraltar water flux decrease during 1960-1970 before the 1970-2009 increase, as found in both observations and the model simulation.

The accuracy of the Gibraltar Strait flow is virtually independent from the accuracy in the rate of change of mass in the basin, river runoff and Bosphorus strait flow, as their effect on the resulting Gibraltar net flux is small compared to the effect of evaporation and precipitation. Uncertainties associated with variations of evaporation and precipitation, underlying the observational derivation of Gibraltar fluxes, are particularly hard to quantify when dealing with decadal timescales. By means of data intercomparison, Mariotti (2010) showed that although differences exist in the amplitude of the evaporation increase from the mid-1990 to late 2010s, this increase is a robust feature of all analyzed datasets; similarly precipitation decrease from the mid-1970 to the mid-1990s is also a robust feature seen in various observational datasets. Hence, the increase in Gibraltar water fluxes over this period we derive based on observational datasets is also likely to be a robust feature although the exact amplitude of the increase needs to be further investigated. An additional boost in confidence in the results for G, is given by the fact that the PROTHEUS system independently simulates decadal $G$ variability that is qualitatively similar to that derived from observations. A priori, because of the model's built-in assumptions (in primis the "equilibrium condition" assumption), the observational and model $\mathrm{G}$ derivations could have significantly differed. A posteriori we find that they don't because, as we find in our observational analysis, the equilibrium assumption is indeed a reasonable one.

Our investigation points to an important role for large-scale climate variability, specifically the Atlantic Multi-decadal Oscillation (AMO) and the North Atlantic Oscillation (NAO) climate modes, in driving observed Gibraltar fluxes which needs to be further investigated. These climate modes appear to influence net water flux at Gibraltar indirectly via the influence they bear on regional evaporation, precipitation and runoff.

Supplementary data to this article can be found online at http:// dx.doi.org/10.1016/j.gloplacha.2012.08.007.

\section{Acknowledgments}

We thank L. Li and an anonymous reviewer for their comments that helped to significantly improve our manuscript. We acknowledge A. Cazenave for helpful discussions, M. Tsimplis and A. Shaw for support in providing the Medar/Medatlas data. This study was partly carried out in the frame of the projects STREMP funded by the DFG/ SPP1257 and TOPO-EUROPE funded by the EU. The PROTHEUS model simulation has been performed as part the CIRCE Integrated Project, funded under the European Commission's Sixth Framework Program.

\section{References}

Adler, R.F., et al., 2003. The version-2 Global Precipitation Climatology Project (GPCP) monthly precipitation analysis (1979-present). Journal of Hydrometeorology 4, 1147-1167.

Adler, Robert F, Guojun, Gu., Huffman, George J. 2012. Estimating Climatological Bias Errors for the Global Precipitation Climatology Project (GPCP). Journal of Applied Meteorology and Climatology 51, 84-99. http://dx.doi.org/10.1175/JAMC-D-11-052.1.

Allan, R., Ansell, T., 2006. A new globally complete monthly historical gridded mean sea level pressure dataset (HadSLP2): 1850-2004. Journal of Climate 19 (22), 5816-5842.

Artale, V., et al., 2010. An atmosphere-ocean regional climate model for the Mediterranean area: assessment of a present climate simulation. Climate Dynamics 35, $721-740$.

Calafat, F., Gomis, D., 2009. Reconstruction of Mediterranean sea level fields for the period 1945-2000. Global and Planetary Change 66, 225-234. http://dx.doi.org/ 10.1016/j.gloplacha.2008.12.015.

Calafat, F.M., Marcos, M., Gomis, D., 2010. Mass contribution to Mediterranean Sea level variability for the period 1948-2000. Global and Planetary Change 73, 193-201. http://dx.doi.org/10.1016/j.gloplacha.2010.06.002.

Carillo, A., Sannino, G., Artale, V., Ruti, P.M., Calmanti, S., Dell'Aquila, A., 2012. Steric sea level rise over the Mediterranean Sea: present climate and scenario simulations. Climate Dynamics. http://dx.doi.org/10.1007/s00382-012-1369-1.

Criado-Aldeanueva, F., Soto-Navarro, X., Garcia-Lafuente, J., 2010. Seasonal and interannual variability of surface heat and freshwater fluxes in the Mediterranean Sea: budgets and exchange through the Strait of Gibraltar Int. Journal of Climatology. http://dx.doi.org/10.1002/joc.2268.

Dell'Aquila, A., Calmanti, S., Ruti, P., Struglia, M.V., Pisacane, G., Carillo, A., Sannino, G., 2012. Impacts of seasonal cycle fluctuations in an A1B scenario over the EuroMediterranean region. Climate Research 52, 135-157. http://dx.doi.org/10.3354/ cr01037.

Efron, B., Tibshirani, R.J., 1993. An introduction to the Bootstrap. Chapman \& Hall, CRC Monographs on Statistics \& Applied Probability.

Enfield, D.B., et al., 2001. The Atlantic Multidecadal Oscillation and its relationship to rainfall and river flows in the continental U.S. Geophysical Research Letters 28, 2077-2080.

Fenoglio-Marc, L., Kusche, J., Becker, M., Fukumori, I., 2007. Comments on "On the steric and mass-induced contributions to the annual sea level variations in the Mediterranean Sea" by D. Garcia et al. Journal of Geophysical Research 112, C12018. http:// dx.doi.org/10.1029/2007JC004196.

Fenoglio-Marc, L., Braitenberg C., Tunini, L, 2012a. Sea level variability and trends in the Adriatic Sea in 1993-2008 from tide gauges and satellite altimetry. Physics and Chemistry of the Earth 40-41, 47-58. http://dx.doi.org/10.1016/j.pce.2011. 05.014

Fenoglio-Marc, L., Rietbroek, R., Grayek, S., Becker, M., Kusche, J., Stanev, E., 2012b. Water mass variation in the Mediterranean and Black Sea. Journal of Geodynamics 59-60, 168-182. http://dx.doi.org/10.1016/j.jog.2012.04.001.

Fenoglio-Marc, L., Kusche, J., Becker, M., 2006. Mass variation in the Mediterranean Sea from GRACE and its validation by altimetry, steric and hydrologic fields. Geophysical Research Letters 33, L19606. http://dx.doi.org/10.1029/2006GL026851.

Flechtner F. (2007) GFZ level-2 processing standards documents for level-2 product release 4, GRACE 327-743, Rev. 1.0

Fofonoff, 1977. Computation of potential temperature of sea water for an arbitrary reference pressure. Deep Sea Research 24, 489-491.

Grayek, S., Stanev, E., Kandilarov, R., 2010. On the response of Black Sea o external forcing: altimeter data and numerical modelling. Ocean Dynamics 60, 123-140.

Greatbatch, R.J., Lu, Y., 2001. Relaxing the Boussinesq Approximation in Ocean Circulation Models. Journal of Atmospheric and Oceanic Technology 1911-1923.

Hurrell, J.W., 1995. Decadal trends in the North-Atlantic Oscillation - regional temperatures and precipitation. Science 269 (5224), 676-679.

Hurrell, J.W., et al., 2003. The North Atlantic Oscillation: Climate Significance and Environmental Impact. p. 279. 
Ishii, M., Kimoto, M., 2009. Reevaluation of Historical Ocea Heat Content Variations with Time-Varying XBT and MBT Depth Bias Corrections. Journal of Oceanography 65, 287-299.

Jones, P.D., et al., 1997. Extension to the North Atlantic Oscillation using early instrumental pressure observations from Gibraltar and south-west Iceland. International Journal of Climatology 17 (13), 1433-1450.

Levitus, S., 1982. Climatological Atlas of the World Ocean. NOAA Professional Paper 13. U.S. Government Printing Office, Washington D.C. 173pp.

Mariotti, A., 2010. Recent Changes in the Mediterranean Water Cycle: A Pathway toward Long-Term Regional Hydroclimatic Change? Journal of Climate 23.

Mariotti, A., Dell'Aquila, A., 2012. Decadal climate variability in the Mediterranean region: roles of large scale forcing and regional processes. Climate Dynamics. http:// dx.doi.org/10.1007/s00382-011-1056-7.

Mariotti, A., Struglia, M.V., Zeng, N., Lau, K.M., 2002. The hydrological cycle in the mediterranean region and implications for the water budget of the Mediterranean Sea. Journal of Climate 15, 1674-1690.

Marshall, J., Adcroft, A., Hill, C., Perelman, L., Heisey, C., 1997. A finitevolume, incompressible navier stokes model for, studies of the ocean on parallel computers. Journal of Geophysical Research 102 (C3), 5753-5766.

Marullo, S., Artale, V., Santoleri, R., 2011. The SST multidecadal variability in the AtlanticMediterranean region and its relation to AMO. Journal of Climate 24, 4385-4401. http://dx.doi.org/10.1175/2011JCLI3884.1.

MEDAR Group, 2002. Medatlas/2002 Database. Mediterranean and Black Sea Database of Temperature Salinity and Bio-chemical Parameters, Climatological atlas, IFREMER Edition.

Menemenlis, D., Fukumori, J., Lee, T., 2007. Atlantic to Mediterranean Sea level difference driven by winds near Gibraltar Strait. Journal of Physical Oceanography 37, 359-376.

Meyssignac, B., Calafat, F.M., Somot, S., Rupolo, V., Stocchi, P., Llovel, W., Cazenave, A., 2011. Two-dimensional reconstruction of the Mediterranean sea level over 1970-2006 from tide gauge data and regional ocean circulation model outputs. Global and Planetary Change 77 (1-2), 49-61. http://dx.doi.org/10.1016/j. gloplacha.2011.03.002

Naeije, M., Scharroo, R., Doornbos, E., Schrama, E., 2008. Global altimetry sea-level service: Glass, NUSP-2 report GO 52320 DEO. NIVR/DEOS, Netherlands.

Pal, J.S., Giorgi, F., Bi, X., Elguindi, N., Solmon, F., Gao, X., Rauscher, S., Francisco, R. Zakey, A., Winter, J., Ashfaq, M., Syed, F., Bell, J., Diffenbaugh, N., Karmacharya, J., Konar'e, A., Martinez, D., da Rocha, R., Sloan, L., Steiner, A., 2007. Regional climate modeling for the developing world: the ictp regcm3 and regcnet. Bulletin of the American Meteorological Society 88, 1395-1409.

Rixen, M., Beckers, J.M., Levitus, S., Antonov, J., Boyer, T., Maillard, C., Fichaut, M., Baloupos, E., Iona, S., Dooley, H., Garcia, M.-J., Manca, B., Giorgetti, A., Manzella, G., Mikhailov, N., Pinardi, N., Zavatarelli, M., 2005. The Western Mediterranean Deep Water: a proxy for climate change. Geophysical Research Letters 32, L12608. http:// dx.doi.org/10.1029/2005GL022702 (2949-2952).

Sanchez-Garrido, J.C., Sannino, G., Liberti, L., Garcia-Lafuente, J., Pratt, L., 2011. Numerical Modelling of Three-Dimensional Stratified Tidal Flow Over Camarinal Sill. Strait of Gibraltar, Journal of Geophysical Research, 116, C12. http://dx.doi.org/ 10.1029/2011JC007093.
Sanchez-Roman, A., Sannino, G., Garcia-Lafuente, J., Carillo, A., Criado-Aldeanueva, F., 2009. Transport estimates at the western section of the Strait of Gibraltar: a combined experimental and numerical modeling study. Journal of Geophysical Research 114, C06002. http://dx.doi.org/10.1029/2008JC005023.

Sannino, G., Carillo, A., Artale, V., 2007. Three-layer view of transports and hydraulics in the Strait of Gibraltar: a three-dimensional model study. Journal of Geophysical Research 112, C03010. http://dx.doi.org/10.1029/2006JC003717.

Sannino, G., Pratt, L., Carillo, A., 2009a. Hydraulic criticality of the exchange flow through the Strait of Gibraltar. Journal of Physical Oceanography 39 (11), 2779-2799. http://dx.doi.org/10.1175/2009JPO4075.1.

Sannino, G., Herrmann, M., Carillo, A., Rupolo, V., Ruggiero, V., Artale, V., Heimbach, P., 2009b. An eddy-permitting model of the Mediterranean Sea with a two-way grid refinement at the Strait of Gibraltar. Ocean Modelling 30 (1), 56-72.

Santer, B.D., Wigley, T.M.L., Boyle, J.S., Gaffen, D.J., Hnilo, J.J., Nychka, D., Parker, D.E., Taylor, K.E., 2000. Statistical significance of trends and trend differences in layeraverage atmospheric temperature time series. Journal of Geophysical Research 105 (D6), 7337-7356. http://dx.doi.org/10.1029/1999JD901105.

Sevault, F., Somot, S., Beuvier, J., 2009. A Regional Version of the NEMO Ocean Engine on the Mediterranean Sea: NEMOMED8 User's Guide. Note de centre ${ }^{\circ} 107$ CNRM, Toulouse, France.

Smith, T.M., Sapiano, M.R.P., Arkin, P.A., 2008. Historical reconstruction of monthly oceanic precipitation (1900-2006). Atmospheres 113, D17115. http://dx.doi.org/ 10.1029/2008JD009851.

Song, T., Hou, T., 2006. Parametric vertical coordinate formulation for multiscale Boussinesq, and non-Boussinesq ocean modeling. Ocean Modelling 11, 298-332.

Soto-Navarro, J., Criado-Aldeanueva, F., García-Lafuente, J., Sánchez-Román, A., 2010. Estimation of the Atlantic inflow through the Strait of Gibraltar from climatological and in situ data. Journal of Geophysical Research 115, C10023. http://dx.doi.org/ 10.1029/2010JC006302.

Struglia, M.V., Mariotti, A., Filograsso, A., 2004. River discharge into the Mediterranean Sea: climatology and aspects of the observed variability. Journal of Climate 17, 4740-4751.

Tonani, M., Pinardi, N., Dobricic, S., Pujol, I., Fratianni, C., 2008. A high-resolution freesurface model of the Mediterranean Sea. Ocean Science 4, 1-14.

Tsimplis, M., Josey, S., 2001. Forcing of the Mediterranean Sea by atmospheric oscillations over the North Atlantic. Geophysical Research Letters 2001 (28), 803-806,5

Uppala, S.M., KÅllberg, P.W., Simmons, A.J., Andrae, U., Bechtold, V.D.C., Fiorino, M. Gibson, J.K., Haseler, J., Hernandez, A., Kelly, G.A., Li, X., Onogi, K., Saarinen, S. Sokka, N., Allan, R.P., Andersson, E., Arpe, K., Balmaseda, M.A., Beljaars, A.C.M., Berg L.V.D., Bidlot, J., Bormann, N., Caires, S., Chevallier, F., Dethof, A., Dragosavac, M., Fisher, M., Fuentes, M., Hagemann, S., Hólm, E., Hoskins, B.J., Isaksen, L., Janssen, P.A.E.M., Jenne, R., Mcnally, A.P., Mahfouf, J.-F., Morcrette, J.-J., Rayner, N.A., Saunders, R.W., Simon, P., Sterl, A., Trenberth, K.E., Untch, A., Vasiljevic, D., Viterbo, P., Woollen, J., 2005. The ERA-40 re-analysis. Quarterly Journal of the Royal Meteorological Society 131, 2961-3012.

Valcke, S., Redler, R., 2006. OASIS3 User Guide. PRISM support initiative report, 4.60 pp. Yu, L., Jin, X., Weller, R.A., 2008. Multidecade global flux datasets from the Objectively Analyzed Air-Sea Fluxes (OAFlux) Project: Latent and Sensible Heat Fluxes, Ocean Evaporation, and Related Surface Meteorological Variables. Woods Hole Oceanographic Institution OAFlux Project Tech. Rep. OA-2008-01. 64 pp. 